\title{
RAÇA E CLASSE NA CLÍNICA PSICOLÓGICA: CONCEPÇÕES DE ESTAGIÁRIOS DO INTERIOR DA AMAZÔNIA OCIDENTAL
}

\author{
RAZA Y CLASE EN LA CLÍNICA PSICOLÓGICA: \\ CONCEPCIONES DE PASANTES DESDE \\ EL INTERIOR DE LA AMAZONIA OCCIDENTAL
}
RACE AND CLASS IN THE PSTCHOLOGICAL CLINIC: INTERNSHIP CONCEPTIONS FROM WESTERN AMAZON COUNTRYSIDE

\author{
Fábio Rodrigues Carvalho ${ }^{1}$ e Leandro Aparecido Fonseca Missiatto ${ }^{2}$ \\ ${ }^{1}$ Centro Universitário UNIFACIMED, Cacoal/RO, Brasil \\ ${ }^{2}$ Faculdade Estácio de Pimenta Bueno, Pimenta Bueno/RO, Brasil
}

\begin{abstract}
RESUMO: Este trabalho resulta de uma pesquisa qualitativa que verificou as percepções de estagiários de Psicologia, através de entrevistas semiestruturadas, sobre questões raciais e de classe social, e como esses fatores se evidenciam na clínica de psicológica. O método de análise das entrevistas foi a Análise de Conteúdo de Bardin. Os resultados indicam: restrito conhecimento temático; dificuldades em relacionar conceitos de forma crítica que abarquem as especificidades desses fenômenos na realidade; escasso repertório teórico-metodológico dos estagiários em identificar tais questões em clínica, limitando-se a utilização de técnicas psicoterapêuticas que não contemplam as especificidades dessas demandas. Por fim, as questões raciais e de classe não são suficientemente discutidas no campo das intervenções clínicas, o que sugere que a formação em Psicologia no interior de Rondônia não contempla aprendizados que habilitem os futuros profissionais à intervenção adequada às questões sócio-raciais.
\end{abstract}

PALAVRAS-CHAVE: Raça; Classe; Estágio específico; Formação em Psicologia; Intervenções clínicas.

RESUMEN: Este trabajo es el resultado de una investigación cualitativa que verificó las percepciones de los pasantes de psicología, a través de entrevistas semiestructuradas, sobre temas raciales y de clase social, y cómo estos factores se evidencian en la clínica psicológica. El método de análisis de las entrevistas fue el Análisis de contenido de Bardin. Los resultados indican: conocimiento temático limitado; dificultades para relacionar críticamente conceptos que engloben las especificidades de estos fenómenos en la realidad; escaso repertorio teórico-metodológico de los aprendices para identificar tales cuestiones en la práctica clínica, limitando el uso de técnicas psicoterapéuticas que no abordan la especificidad de estas demandas. Finalmente, las cuestiones raciales raciales y de clase no se discuten suficientemente en el campo de las intervenciones clínicas, lo que sugiere que la formación en Psicología en el interior de Rondônia no incluye un aprendizaje que permita a los futuros profesionales intervenir adecuadamente en cuestiones socio-raciales. PALABRAS CLAVE: Raza; Clase; Etapa específica; Formación en psicología; Intervenciones clínicas.

ABSTRACT: This work is the result of a qualitative research that verified the perceptions of psychology interns, through semi-structured interviews, about racial and social class issues, and how these factors are evidenced in the Psychology clinic. The method of analysis of the interviews was Bardin's Content Analysis. The results indicate: restricted thematic knowledge; difficulties in critically relating concepts that encompass the specificity of these phenomena in reality; scarce theoretical-methodological repertoire of trainees to identify such issues in clinical practice, limiting the use of psychotherapy techniques that do not address the specificity of these demands. Finally, racial and class issues are not sufficiently discussed in the field of clinical interventions, which suggests that the training in Psychology in the countryside of Rondônia does not include learning that will enable future professionals to intervene appropriately to socio-racial issues.

KEYWORDS: Race; Class; Specific stage; Training in Psychology; Clinical interventions. 


\section{Introdução}

O racismo moderno tem em sua essência a negação total ou parcial da pessoa não branca. Tornar a pessoa não branca como uma vida invisibilizada contou ao longo do tempo com uma miríade de técnicas que não apenas fundamentaram, mas globalizaram a ideia de a pessoa negra ser uma vida inferior. No campo das diversas epistemologias do saber, a pessoa não branca foi desfigurada em humanidade, tornando-se uma vida periférica aos sistemas de direitos humanos (Missiatto, 2021). A produção dessa crise ontológica do continuum humano foi nutrida por discursos biologizantes da raça, como o darwinismo social, que legitimou o avanço imperialista europeu ao redor do mundo (Gonzalez \& Hasenbalg, 1981).

Silvio Almeida (2019) pontua que as noções biologizantes sobre raça, predominantes no século XIX, perderam espaço já na primeira metade do século XX, graças aos eventos da Segunda Guerra Mundial e ao genocídio perpetrado pela Alemanha nazista. Esses eventos contribuíram para que, principalmente na antropologia e na biologia, pesquisas fossem desenvolvidas com o intuito de demonstrar a impossibilidade de categorizar seres humanos em inferiores e superiores por meio de aspectos biológicos e culturais, evidenciando que raça é uma noção essencialmente política. Apesar disso, a ideia de raça permanece quase que inalterada no imaginário social sendo constantemente reativada para naturalizar desigualdades, justificar genocídios e segregar populações oprimidas. Para Gabriel Nascimento (2019), tanto a raça quanto a racialização humana tornaram-se elementos metalinguísticos em nossa sociedade e estão alocadas nas diversas dimensões da vida social e individual, situando-se no campo do simbólico, das narrativas e das políticas que norteiam a vida e as relações sociais.

Muito embora o racismo tenha se tornado cada vez mais um elemento metafísico nas relações humanas, sua origem foi pautada por marcadores específicos, como a cor da pele, traços faciais, territorialidade de nascimento, ou seja, foi pelas diferenças manifestas fenotipicamente que as pessoas não negras subverteram a negritude a status de diferença antagônica e adversarial aos sujeitos brancos, fazendo dessas vidas qualquer coisa que não um humano, materializando a partir do corpo negro os sistemas de exploração e dominação implatado no sul mundial desde o século XVI (Quijano, 2000). A racialização humana na forma que conhecemos hoje se deu com o surgimento da modernidade e com a expansão do capitalismo ao redor do mundo. Para tanto, é pelo avanço do capitalismo mercantil que se desenvolveram as primeiras teorias raciais que atuaram na legitimação da escravização (Willians, 2012).

Ao longo do tempo, essas ideias se constituíram em valores e estes em conduta moral, fazendo com que o racismo se entranhasse nas mais diversas estruturas das sociedades, capilarizando formas de silenciamento e aniquilamento das pessoas de cor. Conforme Frantz Fanon (2008), não existem sociedades mais ou menos racistas, as sociedades são racistas por inteiro. O racismo não deve ser pensado apenas por sua manifestação explícita, mas essencialmente como um elemento estrutural que envolve as esferas econômica, social e psicológica. A marca da pessoa negra inferiorizada deve ser apreendida, desse modo, como uma manifestação histórica, de origem colonial, cujo alcance e profundidade são tão vastos que as mais variadas formas de ser pessoa e ser sociedade atualmente se mostram contaminadas. Nesta lógica, Grada Kilomba (2020) argumenta sobre a realidade violenta do racismo, que se estrutura em uma dinâmica de dominação colonial for talecida 
com a escravização. O racismo envolve uma relação intrínseca entre preconceito, que se articula pela diferença entre sujeitos à hierarquia social e às relações de poder existentes em uma dada sociedade.

No Brasil, o racismo se desenvolveu de forma muito particular, o que chamamos de "racismo à brasileira" diz respeito à ideologia da negação da existência do preconceito racial, o que favorece a ideia de "democracia racial". Esta ideologia emana da colonização do sul-global com a inclusão do "mestiço" no núcleo legal da "grande família". Essa miscigenação seria um índice de integração social, de fusão e de igualdades raciais. Com essa elasticidade do estrato social e a inclusão do "mestiço" como trabalhador semilivre, essa interpretação ganhou força (Fernandes, 1972). Como todo mito construído ideologicamente, a dita "democracia racial" esconde mais do que aparenta, efetivando processos de apagamento e violência simbólica nos corpos negros (Gonzalez, 1983).

O fato é que a miscigenação não significou uma ascensão social para a pessoa preta ou mulata, ela serviu ainda mais para a hegemonia da raça branca, visto que, se delimitavam o espaço de mobilidade social e integração social da população negra. A história evidencia de modo contundente que a branquitude brasileira não proporcionou nenhum modelo de inclusão social que viesse a integrar a população negra na nascente sociedade de classes pós escravidão (Fernandes, 2008). Nessa perspectiva, Clóvis Moura (1988) enfatiza que o aparelho ideológico, repressivo, que dominava o sistema escravagista, estabeleceu as bases materiais do pensamento racista que perdura até hoje, perpetuando a pessoa negra em espaços geográficos e em classes sociais determinadas essencialmente pela cor da pele.

Para entendermos a relação entre raça e classe no contexto brasileiro, precisamos definir primeiramente o que é classe social. Neste artigo trabalhamos com a interpretação marxiana de classe. Karl Marx (1867/1984) entende classe social como a relação direta entre o capital e os meios de produção. Os sujeitos estão localizados no interior da produção capitalista, dividindo-se entre os possuidores e os não detentores dos meios de produção. Nesse contexto, surgem a classe dos exploradores e a classe dos explorados (ou seja, a dos trabalhadores). Essa divisão fez surgir conflitos constantes entre as classes nas sucessivas épocas históricas em decorrência das dominações econômicas e políticas em que foram sujeitos os explorados de classe. Sendo assim, a classe é muito mais que um conceito de economistas ou sociólogos, ela é uma realidade material e histórica que influencia diretamente comportamentos sociais.

De acordo com Lélia Gonzalez e Carlos Hasenbalg (1981), a interpretação predominante por muito tempo nas ciências sociais foi a de que raça e classe eram fenômenos distintos, que deveriam ser analisados em separado. Não se considerava, de fato, a possível coexistência entre racismo, desenvolvimento capitalista e desigualdade social. Entretanto, a raça se constitui como construto social, historicamente definido, funcionando como um dos elementos mais importantes no posicionamento da pessoa negra na hierarquia social.

Renísia Filice (2010) afirma que no Brasil, seria reducionista fazer uma separação de raça e classe sem considerar toda a influência do fator racial na construção do lugar que a população negra ocupa na sociedade de classes. Raça e classe não podem ser desconectadas, vide que se inter-relacionam de forma dialética. Nesse aspecto, José Santos (2005), entende que toda a análise das relações raciais, econômicas e sociais deve se ater a essa questão. 
As desigualdades de raça, apesar de muitas vezes se expressarem de modos distintos das desigualdades de classe, tendem a operar, mas não apenas, como posicionadoras da pessoa negra em lócus inferior à pessoa branca dentro da ordem capitalista. A classe se constitui então como estrutura fundamental pela qual as desigualdades de raça se articulam.

A partir dessa premissa, a possibilidade de acesso a bens e direitos que determinada classe usufrui e a significância desses processos na integração social em sociedades capitalistas, possui a raça como pedra angular, pois o passaporte para direitos é a cor da pele (Tavolaro, 2011). Vale pontuar que, para a população negra no Brasil, a raça sempre foi um marcador fundamental de sua posição na sociedade. Mesmo que a pessoa negra ascenda socialmente, ainda será considerada inferior por uma série de marcadores sociais (Guimarães, 2016). Então, a análise das características de uma determinada situação de classe ou estratificação socioeconômica deve compreender a identificação racial como fator deliberativo dessa conjuntura.

Para Márcio Aguiar (2007), a pobreza no Brasil tem cor. A ascensão social e o acesso aos meios para o desenvolvimento pessoal transpassam diretamente a questão racial ligada à classe social, é a partir dessas conexões que são criados os padrões de acesso ao mercado de trabalho que, em últimas instâncias, cooperarão para delimitar a cor da classe social favorecida e desfavorecida. Desse modo, o preconceito se estrutura como uma distinção não apenas de classe social, mas também da cor de pele.

Conforme a Pesquisa Nacional por Amostra de domicílios (PNAD) realizada pelo Instituto Brasileiro de Geografia e Estatística (IBGE), no ano de 2013, a população negra (autodeclarados pretos e pardos) era maioria no Brasil, cerca de 53,6\% (IBGE, 2015). Outro levantamento feito pelo IBGE demonstrou que, em 2017, havia no país 26,9 milhões de pessoas vivendo com menos de $1 / 4$ do salário mínimo. O grupo dos $10 \%$ com os maiores rendimentos, em sua maioria brancos, concentrava $43,1 \%$ de toda a massa de rendimentos do país. Já o grupo dos 40\% com os menores rendimentos, em sua maioria pessoas negras, tinha apenas 12,3\% dessa massa. Esses dados mostram a grande disparidade econômica entre negros e brancos no Brasil, elucidando a relação íntima entre raça e classe social.

Estudos sobre os impactos do racismo na vida dos indivíduos têm ganhado cada vez mais força mundialmente. Pesquisas sugerem relação intrínseca entre racismo e sofrimento mental, os poucos escritos nacionais que tratam a temática pontuam que a população negra vive em constante sofrimento mental, o que se relaciona geralmente com sua situação social precária e a impossibilidade de pensar possibilidades de superação dessa realidade (Damasceno \& Zanello, 2018). É importante se atentar às particularidades do sofrimento psíquico perante o cenário de discriminação racial. A exposição cotidiana a situações humilhantes e constrangedoras pode acarretar uma série de desorganizações psíquicas e emocionais. Nesse sentido, o racismo se posiciona, consequentemente, como um problema de saúde pública.

A partir disso, cabe destacar que a população negra se mostra como a mais vulnerável diante das desigualdades sociais, o que vai refletir em um limitado acesso a políticas públicas. Isso vai ecoar em processos de marginalização, que limitam o acesso a uma saúde pública de qualidade. Os fatores sociais, como raça e classe, são fundamentais para compreender materialmente como a pessoa negra adoece, os determinantes sociais que estão envolvidos nesse adoecer e o tipo de acesso que ela tem na rede de saúde pública (Werneck, 2016). Para a Psicologia, compreender que o racismo é um agravante social da saúde é fundamental, uma vez que seus fundamentos e objetivos convergem para a compreensão e intervenção de práticas que possam contribuir com o bem-estar do ser humano. 
Pode-se afirmar que os estudos sobre as questões raciais sempre estiveram presentes na construção da Psicologia brasileira. Todavia, é a partir de 1980 que o tema passa a ser entendido não apenas como um fenômeno social, mas também uma temática ligada às relações de poder que causam marginalização e exclusão social de indivíduos negros com significativo impacto na saúde mental dessas populações. Apesar de certa produção ativa sobre a temática racial em Psicologia nos últimos anos, ainda é insuficiente a atenção, engajamento e compreensão sobre o tema dentro dos centros de ensino, o que revela um déficit na formação em Psicologia quanto ao assunto (Schucman \& Martins, 2017).

Nessa lógica, Maria Nascimento e Regina Oliveira (2018) discorrem críticas sobre como é operacionalizada a clínica em Psicologia no Brasil com relação às questões étnico-raciais. Segundo as autoras, a prática clínica é configurada pelo eurocentrismo, abrindo, assim, pouco espaço para relacionar as questões étnico-raciais aos indivíduos, já que as territorialidades e suas peculiaridades são negadas pelas narrativas globalizadas pela cultura eurocêntrica. Para tanto, os aspectos constitutivos da saúde mental que são influenciados pela classe e etnia devem ser considerados como uma ampliação do campo psicológico individual, ou seja, devem estar presentes nos procedimentos da clínica psicológica e adquirem severa importância quando analisados em intersecção do contex to subjetivo com o social.

Rodolfo Maia, Alessandro Santos e Marcelo Santos (2018), em uma pesquisa qualitativa realizada com sete psicólogos e psicólogas do Sistema Único de Assistência Social (SUAS) de Santos/SP, utilizando-se da análise de conteúdo para analisar as entrevistas, constatam através dos resultados, que temáticas étnico-raciais eram abordadas superficialmente na formação desses profissionais, o que evidencia a pouca sensibilidade diante do tema nos atendimentos. Maiara Benedito (2018), em outro estudo, analisa as entrevistas de três psicólogas que trabalham na rede pública e privada de saúde, denotando que apesar dos avanços nos últimos anos ainda falta maior entendimento da dimensão histórica do racismo. Essa falta de entendimento tende a limitar a intervenção psicológica diante dessa problemática.

A Psicologia clínica historicamente manteve um olhar invisibilizador sobre questões envolvendo racismo e violência racial. Estes temas, tratados sempre com menos valia, foram desacreditados e silenciados na escuta terapêutica, nesse aspecto, a Psicologia contribuiu e contribui para a manutenção do racismo, pois quando silencia as vozes de mais da metade da população brasileira marcadas pela violência racial, apaga formas de enfrentamento a essas questões (Rosa \& Alves, 2020). Em pesquisa realizada por Marizete Damasceno (2018) sobre o atendimento clínico em Psicologia de pessoas negras feito por pessoas negras e brancas, teve como um dos temas principais a falta de preparo e conhecimento específico para lidar com demandas raciais dentro da clínica. A pesquisa aponta ainda que mesmo algumas vivências de pessoas negras serem semelhantes a de outros grupos sociais, ainda não é suficiente para que psicoterapeutas consigam atender essas problemáticas de ordem étnica-racial. A falta de preparo reflete o déficit na formação em Psicologia, ainda predominantemente transpassada por teorias européias e estadunidenses que pouco abordam essas questões, construindo nos cursos currículos de cunho tecnicista e pouco sensíveis às realidades sociais.

A esse respeito, Frantz Fanon (2008) denunciou a insuficiência das teorias européias para entender o impacto do racismo na saúde mental, já que que grande parte dessas teorias sobre o sujeito e seu bem-estar estavam vinculadas aos valores do colono, reproduzindo em níveis mais nucleares formas de controle e colonização das subjetividades periféricas. Logo, podemos questionar como se constroem a formação dos diversos cursos de 
Psicologia espalhados pelo Brasil, que pouco pesam temáticas raciais, já que a pedagogia vigorante é a aquela de sentidos coloniais, muito ou totalmente desconectada da vida dos marginalizados do Sul-global.

A pesquisa realizada por Tatiana Espinha (2017) com diversos Projetos Políticos Pedagógicos (PPPs) de cursos de Psicologia do Brasil, demonstra uma formação centrada na clínica, com ênfase no tecnicismo positivista que dificilmente é capaz de articular questões mais críticas quanto aos problemas sociais. O racismo torna-se, nesse contexto, pouco reconhecido nos PPPs, o que explicita o apagamento do debate racial dentro dos cursos de Psicologia de universidades públicas e privadas pelo país. Na região norte, a situação não é diferente, A Psicologia segue os padrões hegemônicos de ensino, com reprodução acrítica de teorias psicológicas, com pouca relação com as questões regionais que envolvem racismo e indigeneidade. Em Rondônia, um trabalho bem elucidativo realizado por Denes etc (2021), que investigou os PPPs de 12 cursos de Psicologia do estado, sendo um de universidade pública e os demais de instituições privadas, evidenciou que poucos currículos abordam temáticas raciais, indígenas, de gênero, entre outras que são próprias das regiões amazônicas. $\mathrm{O}$ foco está em uma formação pragmática, de prioridade clínica, que de forma geral invisibiliza discussões mais aprofundadas sobre esses assuntos dentro do processo formativo. Fica então a questão, como profissionais em Psicologia, podem conseguir identificar sofrimento relacionado ao racismo, se pouco ou nada viram a esse respeito em sua formação?

Sendo assim, o trabalho aqui exposto refere-se a uma pesquisa que teve como objetivo principal verificar a percepção das/dos estagiárias/os) de Psicologia clínica de uma instituição privada de ensino superior do interior de Rondônia sobre os fenômenos da raça e classe e seus impactos na saúde mental das pessoas que recorrem à clínica psicológica.

Destaca-se que a opção pela clínica psicológica deve-se ao fato de essa área de atuação ser tradicionalmente a mais prestigiada na Psicologia, contudo, há evidências da ausência de estudos étnico-raciais nesse campo de atuação profissional. Como clínica psicológica nos referimos ao atendimento psicológico oferecido por um profissional de Psicologia na modalidade individual, em setting terapêutico fechado, cujo objetivo é a superação do sofrimento psíquico, acompanhamento psicoterapêutico ou de outras questões que tenham impacto na subjetividade do cliente/paciente. Esse é um espaço em que muitas abordagens psicológicas podem ser utilizadas, contudo não fazemos predileção por nenhuma delas. O interesse é compreender, para além de especificidades, as percepções de usuários e operadores desta área de saúde mental sobre as temáticas raciais. 


\section{Método}

Este estudo foi submetido ao Comitê de Ética em Pesquisa de uma faculdade privada do interior de Rondônia e aprovado sob parecer CAAE: 19172419.3.0000.5298. Tratase de uma pesquisa qualitativa de caráter descritivo com entrevistas semiestruturadas. O processo de recrutamento dos participantes se deu por meio de uma amostra não probabilística de conveniência, assim os indivíduos empregados nesta pesquisa foram selecionados por estarem prontamente disponíveis. A amostra da pesquisa foi composta por 23 acadêmicos devidamente matriculados no curso de Psicologia de uma instituição de ensino privada, e inscritos no estágio específico em clínica profissional. O curso oferece a partir do $7^{\circ}$ período estágio específico nas abordagens: Análise do Comportamento, Terapia Cognitivo-Comportamental e Psicanálise. Os critérios de inclusão foram: (a) idade igual ou maior que 18 anos; (b) estar devidamente matriculado no curso de Psicologia; (c) ser estagiário na clínica escola. O critério de exclusão foi apresentar prejuízo cognitivo que impeça a compreensão dos objetivos e o processo do estudo.

Os/as participantes foram contatados/contatadas e convidados/convidadas para participarem do estudo diretamente pelos pesquisadores. A coleta de dados ocorreu no período de fevereiro a março de 2020 e consistiu em uma única fase, sendo explicação dos objetivos do estudo, assinatura do Termo de Consentimento Livre e Esclarecido (TCLE), aplicação de questionário sociodemográfico e, por fim, a entrevista semiestruturada. As entrevistas foram realizadas em uma sala pré-reservada na instituição a fim de serem realizadas de forma privada, levando em consideração o conforto do entrevistado e o sigilo da entrevista.

Foram selecionadas 23 pessoas, entrevistadas individualmente. O tempo de entrevista foi de 40 minutos em média. As entrevistas seguiram um roteiro semiestruturado com perguntas sobre a percepção pessoal acerca do que são as questões étnico-raciais e de classe, sobre os procedimentos de entrevista clínica em Psicologia utilizados, se as questões étnico-raciais eram observadas na vivência dos clientes, percepção acerca do público mais vulnerável a essas problemáticas, além da autoconfiança para abordar a temática e estratégias para manejo de tais questões.

Todas as entrevistas foram gravadas e salvas em nuvem, posteriormente foram transcritas e analisadas por meio da Análise de conteúdo de Bardin. A partir da análise das entrevistas, construíram-se as categorias temáticas citadas.

A análise de conteúdo, segundo Laurence Bardin (2010), é um conjunto de técnicas de análise das comunicações que visa obter por meio das mensagens e da descrição destes aspectos qualitativos ou quantitativos que, assim, permitem a inferência acerca das condições em que a mensagem foi produzida.

Utilizaram-se como referência as fases de AC propostas por Bardin (2010): (a) organização da análise; (b) codificação; (c) categorização; (d) tratamento dos resultados, inferência e a interpretação dos resultados. A categorização foi de natureza temática que, segundo a autora, diz respeito a uma regra de recorte de sentido que consiste em descobrir os núcleos de sentido que compõem a narrativa cuja presença pode significar alguma coisa para o objetivo escolhido. 
Para melhor compreensão sobre a aplicação do método apresenta-se como os procedimentos foram realizados:

1. As entrevistas foram convertidas em documentos escritos, processo referente à codificação documental;

2. Conversão dos documentos em elementos teóricos. Nessa fase foram realizadas leituras exaustiva pelos pesquisadores, além de destacamento de trechos, parágrafos ou enunciados que pareceram interessantes aos analistas do discurso;

3. Agrupamentos dos trechos de significação por similaridade. Alguns estudiosos da AC chamam essa fase de agrupamento semântico. Aqui as marcas de significação foram agrupadas em similaridade temática, formando as primeiras categorias;

4. Com base na observação das categorias foram criados eixos temáticos. Algumas categorias foram incorporadas a outras, e mesmo excluídas. Formando então as cinco categorias: (a) Percepção sobre racismo no Brasil; (b) Percepção sobre classe social; (c) Percepção de relação entre raça e classe social; (d) Questão racial e de classe social na clínica em Psicologia; (e) Preparo para lidar com questões étnico-raciais e de classe social na clínica de Psicologia.

5. Os processos $\underline{b}, \underline{c}$ e $\underline{\mathrm{d}}$ tiveram a contribuição de dois juízes, pessoas de fora da pesquisa que observaram a formação das categorias, além de realizarem sugestões e críticas que serviram de base para maior fidedignidade ao método da AC.

Cada categoria foi composta por temas, que serão expostos a seguir.

\section{Resultados e Discussões}

A média de idade da amostra foi de 24 anos, sendo sete indivíduos do sexo masculino e dezesseis do sexo feminino. Onze participantes se autodeclararam brancos, dez pardos e dois negros. Com relação à ocupação, quinze participantes são estudantes, dois professores, um zelador, um educador social, um auxiliar administrativo, um pastor, um escrevente e uma secretária. A renda média foi de 1 a 3 salários mínimos.

\section{Percepção sobre o racismo no Brasil}

Na categoria "Percepção sobre racismo no Brasil", agruparam-se temas que envolviam o entendimento sobre o conceito de raça, racismo e como esse racismo se produz na realidade brasileira. Um tema que se mostrou constante nas entrevistas foi a raça como um conceito de difícil definição:

Rapaz, eu não tenho uma definição acerca disso não, etnia. Agora você me pegou, hein. Vamos lá, etnia, um grupo, e raça, poderia ser caracterizado pela raça humana talvez, etnia, uma tribo, algo assim. Acho que é isso. (W., 22, branco, masc.) 
Outros participantes quando questionados sobre a validade do conceito respondiam de forma pouco objetiva, com argumentos que denotam pouco conhecimento sobre o assunto:

Não sei responder. Sim, na verdade existem pesquisas que comprovam a diferença étnica racial, mas ainda existem teóricos que afirmam que essa diferença não existe, tipo eu não posso definir que eu tenho uma opinião formada, li poucos artigos e poucas matérias, mas sei que existem pesquisas a respeito, mas eu falar assim, poxa, que eu tenho uma opinião formada, assim não. (A., 21 anos, branca, fem.)

As falas dos entrevistados evidenciam certa dificuldade, recorrente até mesmo para estudantes de ciências sociais e humanas, em definir o conceito de raça. Historicamente, esse conceito foi permeado ideologicamente pela ideia da superioridade do europeu branco e a inferioridade das pessoas de cor, alimentada pela validação científica da biologia e antropologia dos séculos XVIII e XIX da existência de grupos humanos inferiores. Mesmo que na contemporaneidade a raça seja estudada como um conceito de origem social e política, ainda essas noções biologizantes perpassam o entendimento comum desse conceito (Guimarães, 2003; Xavier, 2009).

Com relação ao pouco conhecimento sobre o tema evidenciado nas entrevistas, pontua-se que o apagamento e marginalização da cultura e dos saberes da população negra fazem parte de um elaborado projeto político-ideológico que está em curso para a exclusão das pessoas de negras das várias esferas sociais da sociedade, perpetuando um verdadeiro genocídio dessa população no Brasil (Nascimento, 2016).

É importante explicitar que a dificuldade em conceituar o que é raça e as particularidades do processo de discriminação racial no Brasil que se mostraram nas falas dos participantes, indica ao mesmo tempo o dissenso que decorre da complexidade que essas questões carregam, como também expressa a pouca formação específica que se tem com relação a essas demandas, o que reforça a ideia inicial de que há em curso no país uma formação acadêmica amplamente colonialista que atua no apagamento das questões pertinentes às populações negras, limitando profundamente o debate social sobre o tema.

Para Rosa e Alves (2020) a Psicologia cumpriu importante papel na produção do esquecimento histórico de pautas raciais quando negligenciou por muito anos os impactos do racismo na construção da subjetividade da população negra. A Psicologia clínica deu pouca atenção a essas problemáticas, favorecendo para a manutenção do racismo. Além disso, Tatiana Espinha (2017) demonstra em seu estudo o caráter majoritariamente tecnicista dos cursos de Psicologia. Há pouca ênfase sobre as questões étnico-raciais, pode-se dizer que as abordagens são generalistas, existindo poucos cursos que abordam o tema em formato de componente curricular. Tem-se aqui, uma relação direta entre déficit na formação - pautada em teorias nortecêntricas que pouco abordam essas questões - e a pouca compreensão dos processos de discriminação racial por parte de estudantes e profissionais em Psicologia.

A percepção da existência do racismo e como ele se estrutura na realidade brasileira foi outro tema explorado na fala dos participantes:

Existe muito. O Brasil é extremamente racista, só que é um racismo velado, guardado no armário que de vez em quando ele aparece, inclusive está muito em alta né. (B., 32 anos, branca, fem.) 
Outra fala demonstra as formas como o racismo ocorre na sociedade:

Seja de todos os tipos, o racismo não é só de preconceitos verbais ou exclusão social, até a própria cultura é racista, de sempre desvalorizar algumas raças, algumas etnias, eu acredito que é muito presente, embora as políticas, existem muitas políticas públicas nesse sentido, o racismo ele tá presente, no olhar das pessoas pela cultura, nesse olhar preconceituoso, e algumas minorias, e algumas retilineas. (C., 24 anos, parda, fem.)

As falas apontam um entendimento do racismo como algo que existe na realidade brasileira em decorrência de uma cultura racista que se manifesta nas relações sociais, entretanto esse racismo tem sua manifestação de forma velada, inclusive B, aponta aponta que a discussão sobre racismo velado "está muito em alta", indicando uma maior discussão do tema na atualidade. Todavia, como explana Almeida (2019), as interpretações sobre o racismo estão ligadas diretamente a uma ideologia racial que se faz dominante, no caso a pessoa branca é vista como não racializada, já demarcando um processo de racialização muito específico da pessoa de cor. Nesse aspecto, quanto à manifestação do racismo, é importante salientar que a ideia de um racismo pouco explícito, o chamado racismo velado, mostra-se como uma especificidade dessa ideologia racista, que pontua a existência do racismo, mas nega sua prática, mesmo que afirme sua base estrutural que se faz nas relações sociais. Essas bases são pouco visíveis, o que acarreta interpretações individualistas do racismo, envolvendo discussões comportamentais.

No que se refere ao racismo e preconceito que muitas vezes se mostra nas falas dos entrevistados, devemos primeiro distingui-los. Preconceito basicamente pode ser definido como uma atitude hostil contra outra pessoa, geralmente este se fundamenta na concepção de que existem grupos inferiores socialmente. Nessa interpretação, podemos encaixar, entre outros, a homofobia, a gordofobia, o sexismo e o preconceito étnico. O racismo é muito mais que uma atitude em si, é um processo de hierarquização, exclusão e discriminação contra indivíduos que são definidos como diferentes por características físicas externas, que também vai se expressar na inferiozação e marginalização de sua cultura, reduzindo a cultura a noções biologizantes consideradas inferiores (Lima \& Vala, 2004). Nessa lógica, as falas dos participantes demonstram muitas vezes uma limitada diferenciação de racismo e preconceito, em que o racismo se expressa como atitudes e comportamentos para com o outro, o que apaga em muitos casos esse olhar para a estrutura que exclui e discrimina a pessoa negra.

A interpretação dos participantes de um racismo pouco aparente e muitas vezes se confundindo com o preconceito evidencia tipos de análises que não conseguem abarcar categorias mais fundamentais que estruturam e condicionam o racismo, como as relações entre direito, política e economia. Almeida (2019) elucida que é impossível conhecer como o racismo se estrutura na sociedade, sem entender a relação direta entre direito, política e economia para a manutenção e perpetuação do racismo estrutural em nosso país. Assim, não analisar como o racismo se articula nessas esferas é limitar a própria interpretação do sujeito racializado. 


\section{Percepção sobre classe social}

$\mathrm{Na}$ segunda categoria, "Percepção sobre classe social", surgiu o tema que envolve o entendimento sobre o que significa classe social. Entende-se aqui, como menciona Ximenes, Nepomuceno, Cidade e Moura (2015), que a classe social, como lugar de existir do sujeito, implica e sobredetermina de forma complexa o desenvolvimento dos modos de viver, da percepção e do psiquismo. Uma compreensão séria e ampla dessas relações pretende ampliar também ao psicólogo clínico sua compreensão sobre o sujeito que ocupa seu consultório:

Eu já vejo que também é uma questão de categorizar as pessoas, mas aí vem o fator numérico, salário, renda da pessoa. (C., 31 anos, branca, fem.)

As classes sociais também são construções sociais, são as classes sociais e econômicas né as principais, que são os pobres, médios e ricos. (P., 23 anos, parda, fem.)

Entre as falas dos participantes, mostrou-se um comum entendimento em que a classe social possui uma constituição meramente econômica. Max Weber (1977) é um dos autores mais importantes que trata desse tema, segundo o autor, classe social é definida de um ponto de vista econômico, que levará em conta principalmente a oportunidade de o indivíduo dentro de determinado estrato social adquirir bens e oportunidades de rendimento, estando ligada a condições específicas do mercado de trabalho ou mercado de produtos.

Tomando como base o pensamento de Marx (1867/1984), é possível discordar desta interpretação econômica de Weber. Classe social não deve ser interpretada apenas de maneira econômica, mas como uma condicionalidade histórico-social do modo de produção capitalista, que é determinada pela luta de classes entre exploradores e explorados. Entre as falas dos participantes, notou-se a compreensão de classes como grupos distintos, relacionados pelo status econômico, detentores de espaços e identidades diversas, mas não pressupunha qualquer interpretação das condições de exploração de uma classe sobre a outra.

É importante elucidar que classe social no Brasil teve sua formação intrinsecamente relacionada a uma transição de um modo de produção pautado no escravismo, para um nascente capitalismo. Por isso, é impossível debater classe social sem levar em conta a questão racial como importante formador de classes. O negro no Brasil como argumenta Florestan Fernandes (2008) sofreu um processo de marginalização e falta de condições de pré-socialização à nova ordem social capitalista que se instalou no período pós-escravidão. À população negra foi negada real inserção no mercado de trabalho, sendo lançada para os trabalhos mais precarizados, constituindo as grandes massas pauperizadas. Para Jonaz Barcelos (2019) o mito da democracia racial cumpre um papel importante em ocultar os processos de discriminação racial, que se integra as condições de classe da maioria negra em nossa sociedade. Analisar questões de classe apenas como um fator econômico, como ocorreu na maioria das entrevistas, geralmente oculta todo um processo racial de exclusão social que forma a grande maioria dos explorados em nosso país.

Diante disso, é evidente a percepção dos entrevistados de que classe social é um fenômeno econômico, de demarcação de grupos envolvendo a renda, deixando de lado os aspectos determinantes históricos e sociais nessa análise. Quando se analisa a classe apenas por meio da perspectiva econômica, negligencia-se o movimento contraditório e conflitante 
que existe em uma classe social, esta não é uma concepção estática, mas reproduz a própria contradição e movimento concreto da realidade. Neste aspecto, no Brasil a questão racial tem fator determinante na formação e constituição das classes sociais, separando pela cor da pele aqueles que são exploradores e explorados.

\section{Percepção de relação entre raça e classe social}

Na terceira categoria, "Percepção de relação entre raça e classe social", identificou-se nas falas dos participantes o tema da classe social influenciada pela questão racial. Os participantes assinalaram por meio de perguntas disparadoras a existência da influência de questões raciais na estrutura de classe da sociedade brasileira:

Eu acho que tem pessoas mais negras nas periferias e pessoas mais brancas na universidade, no sentido, de privilégios, então, por exemplo, eu sou branco, eu nasci numa família de pais onde os dois têm graduação, eu sou privilegiado no sentido de alguém que nasceu em Cacoal, em um bairro pobre e de pais não formados. A pessoa provavelmente teve muito mais barreiras para chegar até aqui do que eu. Então eu acho que é nesse sentido. (V., 22 anos, branco, masc.)

Outro participante trouxe a seguinte constatação quando questionado a respeito da posição de um indivíduo em uma classe social ser influenciada pela raça:

Acredito que acaba se tornando isso também, porque acaba ficando ali um determinismo né, porque ali é meu convivio, sempre com as mesmas pessoas, porque existe um certo tipo de preconceito até para ele se inserir, por exemplo, a inserção em alguma empresa, a pessoa que é preconceituosa na hora da contratação, acontece de ela não se expandir tanto né, e ficar ali no seu círculo social limitado. (F., 23 anos, branca, fem.)

As falas dos entrevistados demonstram uma compreensão (mesmo que muitas vezes ambígua) da relação intrínseca entre raça e classe, o que transparece uma consciência desses marcadores sociais como fenômenos objetivos. É possível que o debate que se fez nos últimos anos sobre a questão racial, principalmente sobre questões de acesso a oportunidades e lugares muitas vezes ocupados historicamente por pessoas brancas, como as universidades, tenha desenvolvido esse maior interesse e consciência da temática. Como argumenta José Backes (2006), raça e classe no Brasil possuem uma estreita relação, que se mostra nas desigualdades de acesso a empregos, educação, saúde e renda. O acesso a universidades, por meio das políticas de ações afirmativas, surge como fortalecedor da identidade negra, possibilitando uma maior discussão sobre a questão racial e o lugar da pessoa negra na sociedade de classes.

O entendimento de que existe uma influência da raça com relação à posição do indivíduo em uma dada classe social é significante, todavia não aparece nas entrevistas uma interpretação do por que a pessoa negra tem seu acesso limitado no trabalho ou ao ensino. Quanto à questão da inserção social da população negra, na divisão social do trabalho no Brasil, à questão racial, limitou o acesso ao trabalho, reduzindo a mobilidade social, reservando trabalhos que a pessoa branca por vários motivos descarta ou despreza. Nisso, os negros vão sofrer, como grupo, as principais explorações de classe dentro de uma sociedade capitalista competitiva, sendo jogados em periferias, tendo pouco acesso à educação, tornando-os menos competitivos nesse sistema (Moura, 1983). 
É preciso pontuar que a dificuldade de uma interpretação mais profunda dessas questões se deve muito à própria dinâmica de apagamento das discussões sobre questões raciais na sociedade. Sendo assim, é interessante resgatar o papel do mito da democracia racial nesse aspecto. Segundo Florestan Fernandes (1972) o mito da democracia racial coloca o Brasil como um país racialmente neutro, por sua miscigenação, não precisa discutir de forma aprofundada a temática racial. Como resultado dessa ideologia, apesar dos avanços das discussões nos últimos tempos, ainda há pouca compreensão sobre a estrutura racista em nosso país.

\section{Questão racial e de classe social na clínica em Psicologia}

A quarta categoria, "Questão racial e de classe social na clínica em Psicologia", objetivou trabalhar temas relacionados à percepção da influência da raça e da classe social nas experiências dos pacientes e se eles conseguem identificar essas demandas nos pacientes atendidos.

Marizete Gouveia e Valeska Zanello (2019) apresentam que o racismo, em seu caráter estrutural e estruturante, já se instalou em todas as camadas das relações sociais, e as epistemologias não escapam disso. Entre os entrevistados, os fatores relacionados à raça e classe social pareciam distantes do ambiente da clínica psicológica:

Depende, nos casos que eu tive não, porque o sofrimento psíquico do cliente não era relacionado a nenhuma classe social, nenhuma questão étnico racial. (A, 21, negra, fem.)

Elizama Costa e Patrícia Oliveira (2019) argumentam que as questões raciais implicam diretamente em conflitos e sofrimentos psíquicos ou, como pontua Fanon (2008), o racismo como se dá invade as estruturas psíquicas do homem moderno, assim como rege seus desenvolvimentos. Ficou evidente por meio das falas dos participantes que, independente da cor dos entrevistados, nenhum inicia o assunto sobre questões raciais e de classe social na clínica, é sempre algo trazido pelo paciente e se o mesmo não apresenta essa demanda de forma explícita, pouco será feito para facilitar o desenvolvimento desse assunto com ele. Neste seguimento, Alessandro Santos e Lia Schucman (2015) argumentam que essa postura pouco crítica, que muitas vezes demonstra total desconhecimento do tema, de estudantes de Psicologia, relaciona-se ao limitado repertório teórico adquirido sobre o racismo no processo de formação no ensino regular e superior, levando em conta que vivemos em uma sociedade que tem dificuldade em ouvir, opinar e debater sobre raça, relações raciais e racismo. Então, temos cursos de Psicologia que reproduzem apagamentos epistémicos, reforçando direta e indiretamente estruturas sociais racistas.

Para Gouveia e Zanello (2019), a formação do psicólogo no Brasil carece de um entendimento de como as estruturas sociais racistas tendem a influenciar o sofrimento psíquico. Mesmo que essas demandas possam atravessar as experiências concretas dos pacientes, em sua maior parte são negligenciadas ou trabalhadas de maneira inadequada na psicoterapia.

Boa parte dos entrevistados relataram nunca terem presenciado em clínica esse tipo de demanda. Alguns argumentam que essas demandas podem aparecer indiretamente, e o próprios pacientes podem não ter consciência dessas questões: 
Olha eu acho que a questão do racismo quando vem para o atendimento, ela veio meio que velada, porque os próprios pacientes eles ouvem tanto isso no decorrer do tempo que eles acabam acreditando nisso, então eles meio que, o preconceito racismo ele vem meio que velado para seção, porque a pessoa não tem força ali na hora para descobrir o que ela tá vivendo. (M, 22 anos, parda, fem.)

Neusa Santos (1983) argumenta que a violência do racismo é uma constante na vida da pessoa negra, nisso é uma necessidade da mesma criar estratégias de defesa psicológicas para o seu enfrentamento, que podem envolver uma aceitação da mistificação, a negação das tradições e da cultura negra ou não falar sobre o assunto. A realidade do racismo pode sim contribuir diretamente para o ocultamento na clínica da problemática racial, todavia o despreparo dos profissionais também se torna um fator determinante na manutenção do racismo. Como Santos e Schucman (2015) afirmam, existe a necessidade de um "letramento racial" que possa abarcar nas formações em Psicologia essas demandas de forma específica e aprofundada.

São sintomáticos a pouca percepção e o apagamento de questões raciais nos atendimentos clínicos dos entrevistados. A clínica é percebida como um espaço que lida com subjetividades de forma individual. Apesar de a Psicologia como ciência buscar o entendimento do sujeito por meio do seu aspecto biopsicossocial, o que se vê muitas vezes na prática é a utilização de metodologias e interpretações do sujeito que o individualizam, apagando sua relação direta com a realidade material. Silvia Lane (1989) pontua que se a Psicologia focar apenas no indivíduo como causa e efeito de sua individualidade ela se torna reducionista, ideológica e conservadora, seria então uma ciência sem nenhuma responsabilidade com qualquer mudança social. Destarte, fazer uma clínica sem responsabilidade de mudança social, é fazer uma clínica vazia de sentido real.

\section{Preparo para lidar com questões étnico-raciais e de classe social na clínica em Psicologia}

$\mathrm{Na}$ quinta e última categoria, "Preparo para lidar com questões étnico-raciais e de classe social na clínica em Psicologia”, as respostas concentraram-se em mencionar a momentaneidade, "no momento não", "ainda não", "estou em preparação”, evidenciando o tema da pouca preparação para lidar com essas demandas:

Queria estar mais preparada, mas eu acredito que ainda não, acredito que eu teria que aprofundar muito mais, porque é muito diferente do que a pessoa negra sofre, então tipo assim, a gente não sente na pele o que é, então tipo assim, a gente precisa procurar um pouco mais conhecimento de saber mesmo como que o outro vive e o que acontece na sua vivência... (T, 26 anos, branca, fem.)

A formação deficitária foi uma das problemáticas mais apontadas pelos estagiários. A ausência de disciplinas específicas que tratem as contradições de raça e classe para a clínica psicológica foi declarada como uma questão central para a falta de conhecimento sobre o assunto, outros estudos já apontam esse déficit problemático da formação do psicólogo brasileiro. Segundo Santos e Schuman (2015), essa ausência do debate sobre o racismo na clínica psicológica, por exemplo, propõe uma percepção de irrelevância diante desse assunto. 
Para Maia, Santos e Santos (2017), a formação em Psicologia no Brasil não possibilita ao estudante um conhecimento dos aspectos sócio-históricos que determinam sua própria formação. A Psicologia se desenvolveu no Brasil como legitimadora de discursos ideológicos dominantes, tendo negligenciado por muitos anos um real debate sobre questões raciais. Nisso, como afirma Gouveia e Zanello (2019), fazemos uma Psicologia colonizada, que tem em seu discurso universalizante o tratamento do sofrimento humano, mas deixa de lado as especificidades desse humano (mestiço, preto, indígena), não tratando os malefícios causados por doenças sociais como o racismo. Pratica-se o racismo por omissão e, até o momento, parece que a Psicologia Brasileira está satisfeita com esse cenário.

\section{Conclusão}

A Psicologia no Brasil ainda reproduz em seus apagamentos epistêmicos o racismo estrutural em nossa sociedade, ao contemplar um modelo de formação tradicionalmente eurocêntrico. O contato aprofundado com essas temáticas é uma necessidade que os cursos de Psicologia não podem mais adiar. As falas dos 23 entrevistados demonstram um despreparo que tende a ser reproduzido na realidade profissional, ajudando a reforçar o racismo estrutural em nosso país.

Através das análises apresentadas, evidenciaram-se alguns pontos importantes, os estagiários e estagiárias demonstraram possuir algum conhecimento sobre as temáticas apresentadas, contudo ainda superficial, o que sugere reflexos do surgimento dessas discussões no cenário acadêmico de Psicologia nos últimos anos. Todavia, ficou evidente a dificuldade de relacionar os conceitos de uma forma crítica, que abarque as especificidades desses fenômenos em uma realidade concreta. Outro ponto interessante, é o limitado repertório que esses estagiários têm para identificar essas questões em clínica, restringindo-se a utilização de técnicas psicoterapêuticas que não abarcam a especificidade dessas demandas.

$\mathrm{O}$ apagamento de discussões sobre questões raciais nos centros de ensino se mostra como mais um sintoma da exclusão do debate sobre raça e racismo em nosso país, o que se relaciona diretamente ao mito da democracia racial. Enquanto esse mito prosperar, as questões raciais ainda vão continuar a ser negligenciadas, produzindo mais e mais profissionais despreparados e incapazes de lidar com essas demandas.

Por fim, os déficits aqui encontrados evidenciam ainda mais os limites do ensino em Psicologia no Brasil sobre questões raciais e de classe social. Ainda fazemos uma Psicologia colonizada por teorias eurocêntricas e norte-americanas, que não abrangem as particularidades da realidade brasileira transpassada por um racismo estrutural, que exclui pessoas negras do acesso à saúde mental em nosso país. A formação dos currículos em Psicologia que enfatizam esses tópicos de forma sistemática e específica pode ser um caminho para o desenvolvimento de um maior repertório na formação desses futuros profissionais. Os resultados indicam a necessidade de materializar em ações efetivas a possibilidade de construir uma clínica em Psicologia realmente integrativa e humanizada. 


\section{Referências}

Aguiar, Márcio Mucedula (2007). A construção das hierarquias sociais: classe, raça, gênero e etnicidade. Cadernos de Pesquisa do Cdhis, 37(36), 83-88. Recuperado de https://portal.ufgd. edu.br/setor/neab/documentos-baixar

Almeida, Silvio (2019). Racismo Estrutural. Polén.

Backes, José Licínio (2006). Articulando raça e classe: efeitos para a construção da identidade afrodescendente. Educ. Soc, 27(95), 429-433. https://doi.org/http://dx.doi.org/10.1590/ $\underline{\text { S0101-73302006000200006. }}$.

Bardin, Laurence (2010). Análise de conteúdo. Edições 70.

Benedito, Maiara Souza (2018). A relação entre psicologia e racismo: As heranças da clínica psicológica. Dissertação de Mestrado, Instituto de Psicologia, Universidade Federal de São Paulo, São Paulo. Doi: 10.11606/D.47.2018.tde-04092018-102726. Recuperado de https://teses.usp. br/teses/disponiveis/47/47134/tde-04092018-102726/pt-br.php

Barcelos, Jonaz Gil (2019). A questão racial e a formação da classe trabalhadora no Brasil. In Anais III Seminário Nacional de Serviço Social, Trabalho e Política Social. Resumos de comunicações científicas Florianópolis: UFSC. Recuperado de https://repositorio.ufsc.br/hand$\underline{\text { le/123456789/202607 }}$

Costa, Elizama Franciane \& Oliveira, Patrícia Alessandra (2019). O sofrimento psíquico causado pelo racismo e o seu impacto na subjetividade. REVISTA UNINGÁ, 56(1), 114-130. Recuperado de http://revista.uninga.br/index.php/uninga/article/view/444

Damasceno, Marizete Gouveia (2018). Onde se esconde o racismo na psicologia clínica? a experiência da população negra na invisibilidade do binômio racismo e saúde mental. Tese de Doutorado, Programa de Pós-graduação em Psicologia Clínica e Cultura , Universidade de Brasília, Brasília.

Damasceno, Marizete Gouveia \& Zanello, Valeska M. Loyola (2018). Saúde Mental e Racismo Contra Negros: Produção Bibliográfica Brasileira dos Últimos Quinze Anos. Psicologia: Ciência e Profissão, 38(3), 450-464. https://dx.doi.org/10.1590/1982-37030003262017

Denes, Daylan Maykiele, Carvalho, Fábio Rodrigues, Souza, Iago Brilhante, Missiatto, Leandro Fonseca, \& Silva, Leila Gracieli (2021). A formação em Psicologia na Amazônia Ocidental- entre a dominação hegemônica e as desigualdades: uma análise das grades curriculares de Rondônia. In Eliane G. Fernandes, Fabrício R. Lopes, \& Leila G. Silva (Orgs.), Insurgências amazônicas: saberes e fazeres em Psicologia. EDUFRO. Recuperado de https:// edufro.unir.br/uploads/08899242/Colecao\%20pos\%20UNIR/05\%20INSURGeNCIAS\%20 AMAZONICAS.pdf.

Espinha, T. G. (2017). A temática racial na formação em psicologia a partir da análise de projetos políticos-pedagógicos: silêncio e ocultação. Tese de doutorado, Programa de Pós-graduação em Educação, Universidade Estadual de Campinas, Campinas, SP.

Fanon, Frantz (2008). Pele negra, máscaras brancas. EdUfba.

Fernandes, Florestan (1972). O Negro no Mundo dos Brancos. Difusão Européia do Livro.

Fernandes, Florestan (2008). A integração do negro na sociedade de classes. Globo.

Filice, Renísia Cristina Garcia (2010). Raça e classe na gestão da educação básica brasileira. Tese de Doutorado, Programa de Pós-graduação em Educação, Universidade de Brasília, Brasília. 
Gonzalez, Lélia \& Hasenbalg, Carlos (1981). Lugar de negro. Marco Zero.

Gonzalez, Lélia (1983). Racismo e sexismo na cultura Brasileña. ANPOCS.

Guimarães, Antonio Sérgio Alfredo (2003). Como trabalhar com” raça” em sociologia. Educação e pesquisa, 29(1), 93-107. https://doi.org/10.1590/S1517-97022003000100008

Guimarães, Antonio Sérgio Alfredo (2016). Formações nacionais de classe e raça. Tempo sociológico, 28(2), 161-182. https://doi.org/http://dx.doi.org/10.11606/0103-2070. ts.2016.109752.

Gouveia, Marizete \& Zanello, Valeska (2019). Psicoterapia, raça e racismo no contexto brasileiro: experiências e percepções de mulheres negras. Psicologia em Estudo, 24, e42738. https://dx.doi.org/10.4025/psicolestud.v24i0.42738

Instituto Brasileiro de Geografia e Estatística. (2015). Pesquisa nacional por amostra de domicílios: sintese de indicadores 2013 (2a ed.). Autor. Recuperado de https://biblioteca.ibge. gov.br/visualizacao/livros/liv94414.pdf

Kilomba, Grada (2020). Memórias da plantação: episódios de racismo cotidiano. Cobogó.

Lane, Silvia (1989). A Psicologia social e uma nova concepção de homem para a "Psicologia". In Silvia Lane \& Wanderley Codo (Orgs.), Psicologia social: o homem em movimento (pp. 10-19). Brasiliense.

Lima, Marcus Eugênio Oliveira \& Vala, Jorge (2004). As novas formas de expressão do preconceito e do racismo. Estud. Psicol, 9(3), 401-411. https://doi.org/10.1590/S1413$\underline{-294 \times 2004000300002}$

Maia, Rodolfo Luis Almeida, Santos, Alessandro Oliveira, \& Santos, Marcelo Jardim (2018) As Relações Étnico- Raciais no Cotidiano de Psicólogos do Sistema Único de Assistência Social (SUAS) da Cidade de São Paulo. In Atualidades na investigação em psicologia epsicanálise. Blucher. doi:10.5151/9788580393101-02 Recuperado de https://repositorio.usp. br/item/002888644

Marx, Karl (1867/1984). O Capital: crítica da economia política (R. Barbosa \& F. R. Kothe, trad.). Abril Cultural.

Moura, Clóvis (1983). Brasil: raízes do protesto negro. Global.

Moura, Clóvis (1988). Sociologia do negro brasileiro. Ática.

Missiatto, Leandro Fonseca (2021). Colonialidade normativa. Appris.

Nascimento, Abdias (2016). O genocídio do negro brasileiro: processo de um racismo mascarado. Perspectiva S. A.

Nascimento, Gabriel (2019). Racismo linguístico: os subterrâneos da linguagem e do racismo. Letramento.

Nascimento, Maria da Conceição \& Oliveira, Regina Marques de Souza (2018). A clinica e seus desafetos: pactos e omissões nos estudos sobre o negro no Brasil. Revista da Associação Brasileira de Pesquisadores/as Negros/as, 10(24). Recuperado de http://abpnrevista.org.br/revista/index.php/revistaabpn $1 /$ article/view/577

Quijano, Aníbal (2000). Colonialidad del poder, eurocentrismo y América Latina. In E. Lander (Org.), A colonialidade do saber: eurocentrismo e ciências sociais. Perspectivas latinoamericanas (pp.118-142). Colección Sur. 
Rosa, Evellyn Gonçalves \& Alves, Miriam Cristiane (2020). Estilhaçando a Máscara do Silenciamento: Movimentos de (Re) Existência de Estudantes Negros/Negras. Psicologia: Ciência e Profissão, 40, 01-14. https://doi.org/10.1590/1982-3703003229978

Santos, Alessandro Oliveira \& Schucman, Lia Vainer (2015). Desigualdade, relações raciais e a formação de psicólogo(as). EPOS 6(2), 117-140. Recuperado de http://pepsic.bvsalud.org/ scielo.php? script $=$ sci $\operatorname{arttext} \& p i d=S 2178-700 X 2015000200007 \& \operatorname{lng}=p t \& n r m=i$ iso

Santos, José Alcides Figueiredo (2005). Efeitos de classe na desigualdade racial no Brasil. Dados, 48(1), 21-65. https://doi.org/10.1590/S0011-52582005000100003

Santos, Neusa Souza (1983). Tornar-se negro: as vicissitudes da identidade do negro brasileiro em ascensão social. Graal.

Schucman, Lia Vainer \& Martins, Hildeberto Vieira (2017). A Psicologia e o Discurso Racial sobre o Negro: do "Objeto da Ciência" ao Sujeito Político. Psicologia: Ciência e Profissão, 37(nspe.), 172-185. https://dx.doi.org/10.1590/1982-3703130002017

Tavolaro, Lília Gonçalves Magalhães (2011). Raça, classe e cultura no contexto das políticas de ação afirmativa: um esforço teórico-crítico a respeito da raça. Sociedade e Cultura, 13(2), 287-298. https://doi.org/10.5216/sec.v13i2.13432

Weber, Max (1977). Classe, status, partido. In Otávio G. Velho, M. Palmeira, \& A. Bertelli, (Orgs.), Estrutura de classes e estratificação social (7 ${ }^{\mathrm{a}}$ ed., pp. 1-175). Zahar.

Werneck, Jurema (2016). Racismo institucional e saúde da população negra. Saúde e Sociedade, 25(3), 535-549. https://doi.org/10.1590/s0104-129020162610

Willians, Eric (2012). Capitalismo e escravidão. Companhia das Letras.

Xavier, Regina Célia Lima (2009). Raça, civilização e cidadania na virada do século XIX e início do século XX [Resumo]. In Anais do IV Encontro Escravidão e Liberdade no Brasil Meridional (p. 01). Universidade Federal do Paraná.

Ximenes, Verônica M., Nepomuceno, Bárbara B., Cidade, Elívia C., \& Moura, James F. (2016). Implicações psicossociais da pobreza: diversidades e resistências. Expressão Gráfica e Editora. 


\section{FÁBIO RODRIGUES CARVALHO \\ https://orcid.org/0000-0001-6397-7925}

Discente de Psicologia no Centro Universitário UNIFACIMED. Cacoal/

RO, Brasil

E-mail: fabio.relativity@gmail.com

\section{LEANDRO APARECIDO FONSECA MISSIATTO \\ https://orcid.org/0000-0002-6532-735X}

Doutorando em Psicologia Clínica pela Universidade do Vale do Rio dos Sinos/ Unisinos. Mestrado em Psicologia na Universidade Federal de Rondônia/ UNIR. Vice-líder do LARIS, Laboratório de Relações Interpessoais e Saúde do Departamento de Psicologia da Universidade Federal de Rondônia/UNIR. Analista processual na especialidade de Psicologia do Tribunal de Justiça do Estado de Rondônia. Docente da Escola da Magistratura de Rondônia/ Emeron, Cacoal/RO, Brasil. Docente do curso de Psicologia da Faculdade Estácio de Pimenta Bueno/FAP, Pimenta Bueno/RO, Brasil.

E-mail: leandro afonseca@hotmail.com

\begin{tabular}{|l|l|}
\hline \multirow{3}{*}{ Histórico } & Submissão: 12/04/2021 \\
& Revisão: 26/10/2021 \\
& Aceite: 28/10/2021 \\
\hline & Concepção: F.R.C. \\
& Coleta de dados: F.R.C. \\
& Análise de dados: F.R.C.; L.A.F.M. \\
Contribuição & Elaboração do manuscrito: F.R.C.; L.A.F.M. \\
dos autores & Revisões críticas de conteúdo intelectual importante: \\
& L.A.F.M. \\
& Aprovação final do manuscrito: F.R.C.; L.A.F.M. \\
\hline \multirow{3}{*}{ Financiamento } & $\begin{array}{l}\text { O presente trabalho foi realizado com apoio financeiro do Centro } \\
\text { Universitário - UniFacimed, por meio do Programa de Iniciação } \\
\text { Científica - PIC Edital 2019/2020. }\end{array}$ \\
\hline $\begin{array}{l}\text { Aprovação, ética } \\
\text { e consentimento }\end{array}$ & $\begin{array}{l}\text { O estudo foi aprovado pelo Comitê de Ética em Pesquisa do } \\
\text { Centro Universitário - UnIFACIMED, com parecer CAAE: } \\
\text { 19172419.3.00oo.5298. }\end{array}$ \\
\hline
\end{tabular}

